Crops

Research Note

\title{
THE USE OF GLYPHOSATE IN ASPARAGUS - PRELIMINARY OBSERVATIONS
}

\author{
T. I. COX \\ Horticultural Research Centre \\ Levin
}

SUMMARY

The subsequent yield of asparagus (Asparagus officinalis) was not affected by $2 \mathrm{~kg} / \mathrm{ha}$ of glyphosate applied overall at various times during winter or as a directed spray in autumn. Yield was seriously reduced by an overall spray in autumn.

\section{INTRODUCTION}

A consequence of the quick expansion of asparagus growing into new and, as yet largely unproven parts of the country is the appearance of weeds which are difficult to control. Often the main problems in the newly established crop will be caused by regrowth of such weeds as couch (Agropyron repens), Californian thistle (Cirsium arvense) and paspalum (Paspalum dilatatum). When faced with burgeoning weeds, growers look for the most effective herbicides and may accept some risk of crop damage in order to regain good weed control. Glyphosate is often used in this way though it is known that it can cause severe damage to young asparagus. Yang (1979) reports little tolerance to $100 \mathrm{ppm}$ concentration when applied in vitro to bud segments, crowns, unrooted plantlets and seeds. In vivo, young seedlings were killed by a 10,000 ppm glyphosate spray.

Glyphosate could be a very useful tool in asparagus management providing the circumstances of safe crop use can be adequately defined. This paper reports first season results from a long-term investigation of applications at different times of year on asparagus under field conditions.

\section{METHODS AND MATERIALS}

One-year-old crowns of cv. Rutgers Beacon were planted in late August 1979 in single-row plots in a six-replicate layout. Rows were $1.5 \mathrm{~m}$ apart and each plot contained 15 crowns spaced $40 \mathrm{~cm}$ apart in the row. During the first growing season an intensive programme was devised to maintain good weed control. After planting, before emergence, diuron $1.0 \mathrm{~kg} / \mathrm{ha}$ and metribuzin $0.4 \mathrm{~kg} / \mathrm{ha}$ were applied; in early December this was followed by monolinuron $0.5 \mathrm{~kg} / \mathrm{ha}$ and methabenzthiazuron $1.0 \mathrm{~kg} / \mathrm{ha}$ with a similar application of this mixture repeated in mid-February. On several occasions during the season the trial was hand weeded to clean up surviving weeds. The crop grew vigorously and uniformly to a height of $1.5 \mathrm{~m}$ during the spring and summer. During the winter amitrole $\mathrm{T} 3 \mathrm{~kg} / \mathrm{ha}$ was sprayed between the plot rows and simazine $1 \mathrm{~kg} / \mathrm{ha}$ applied overall.

Glyphosate treatments were applied at different stages from autumn 1980 onwards, as detailed in Table 1 . On each occasion glyphosate was applied at $2 \mathrm{~kg} / \mathrm{ha}$ in a spray volume of 300 litres/ha and at a pressure of $200 \mathrm{kPa}$ using a propane-powered experimental sprayer. The two methods of application, overall and directed, are explained in Figure 1. Foliar effects of the spray were noted after the overall treatment in April. The trial was harvested on four occasions during the latter half of September when weights and numbers of spears were recorded on all treatments.

Proc. 34th N.Z. Weed and Pest Control Conf. 
Crops

Fig 1: Details of spray techniques used for April application (same jet arrangements used in absence of foliage in May, July and August).

$\longleftarrow 75 \mathrm{~cm} \longrightarrow$

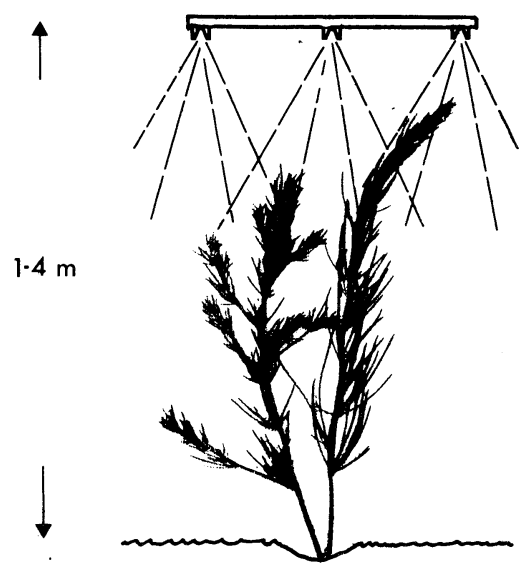

Overall

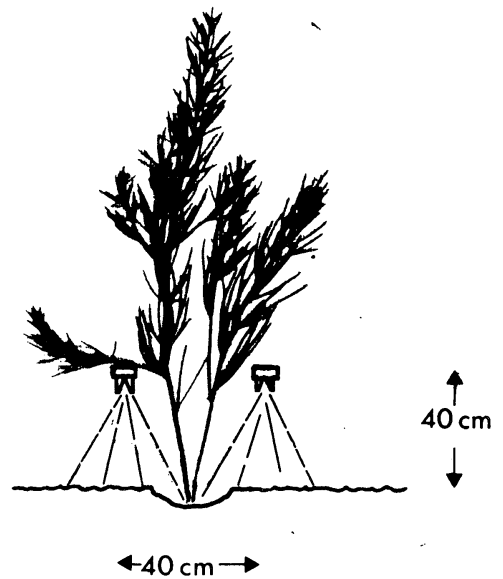

Directed

Fig 2: Asparagus yields in September after previous glyphosate treatment.

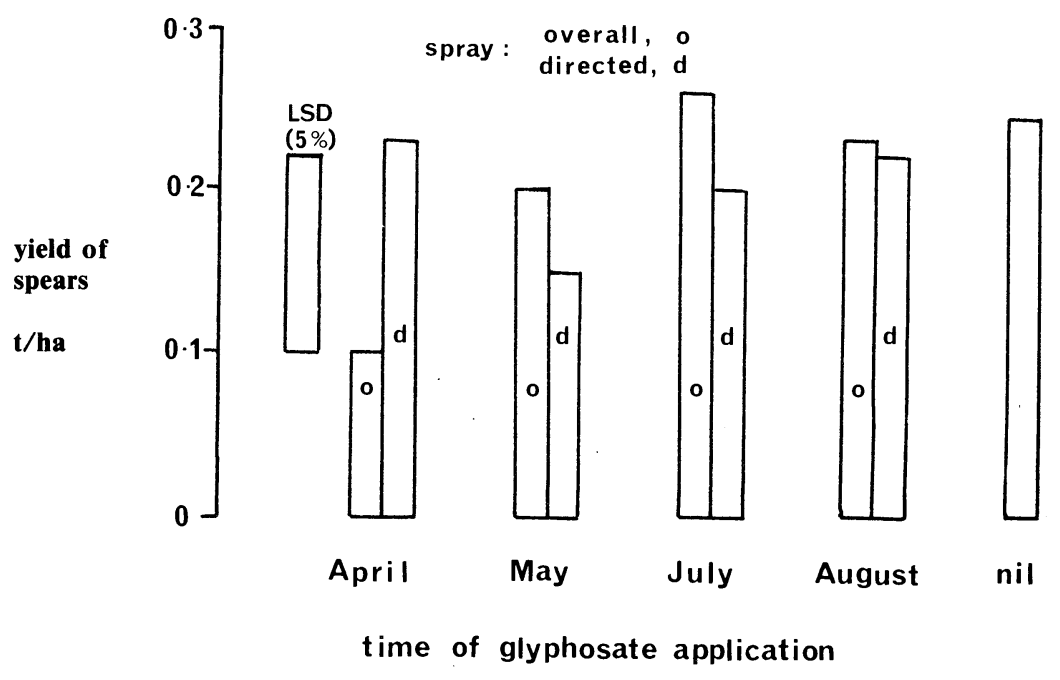




\section{Crops}

TABLE 1: Method and time of application of glyphosate.

Applied both overall and directed at the following times.

April, - before removing foliage

May, - after removing foliage

July, - during maximum dormancy

August, - just before spear emergence.

Untreated

\section{RESULTS}

The earliest glyphosate application, sprayed over the asparagus foliage in late April, caused chlorosis or necrosis of the fern tips. Within two weeks of spraying, however, the fern on all plots was dying back naturally and the treatment effect became less obvious. Subsequent treatments were applied in the absence of foliar growth so weight and number of spears next spring were the only measures of possible effect. Figure 2 shows treatment yields as total weight of spears. The overall glyphosate treatment in April gave the lowest yield, significantly less than the unsprayed treatment, the directed treatment in April and the overall treatments in July and August. A similar trend was obtained in spear numbers and these data are not presented.

\section{DISCUSSION}

These results clearly demonstrate the damaging effect of glyphosate when it is applied to asparagus foliage in autumn; they also suggest safe ways of using the chemical in the crop during the autumn, winter and spring. The treatments will be repeated annually as the crop matures to determine the risk of crop damage to older plants.

A further treatment consists of applying glyphosate just after the final spear cut in spring but no results are yet available.

\section{REFERENCE}

Yang, Hsu-Jen, 1979. Effect of glyphosate on Asparagus officinalis L. shoot and root development in vitro and in vivo. Proc. 5th International Eucarpia Asparagus Symposium, Geisenheim, Fed. Rep. Germany. Ed. G. Reuther, 171-9. 